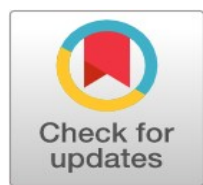

\title{
$X$ strategic resources, use of performance measurement system and hospital performance in West of Indonesia
}

\author{
Alfiandri * \\ Swiss German University, Tangerang, Indonesia
}

\author{
Index Terms \\ Strategic resources \\ Performance measurement \\ Hospital performance \\ Received: 8 August 2016 \\ Accepted: 19 November 2016 \\ Published: 27 February 2017
}

\begin{abstract}
Resource based theory describes, explains and predicts how firms can achieve sustainable competitive advantages through acquisition and control over resources. This study examines the role of Performance Measurement Systems' (PMS) usage either diagnostically or interactively in further enhancing hospitals' performance in managing their strategic resources. PMS acts as tools for measuring firms' performance through monitoring, controlling and legitimizing company resources, and is viewed as learning devices to enhance firms' performance. Using diagnostic PMS, the managers can control and monitor the resources based on pre-set standard performance, while interactive PMS provides feedback through frequent communication and observes new strategies that enhance the strategic resources' performance which leads to firms' performance. Data were collected from 160 hospitals in Sumatra Island and Jakarta using structured questionnaire. The result of path analysis using AMOS 18 reveals that alternative model is a fit model than a based model. The findings show that strategic resources of Indonesian hospitals (human resource, structural resource and physical resource) should be managed independently. PMS is used diagnostically or dynamically (combination of diagnostic and interactive ways) in managing each of the resources to enhance the quality of healthcare services and subsequently lead to financial performance of the hospital.
\end{abstract}

\section{INTRODUCTION}

Issues on the need to implement new performance measurement systems (PMSs) that support an organization's objectives and strategies have been steadily capturing the attention of both academicians and practitioners for the past few years. According to Merchant \& Van der Stede (2007), new PMSs allow companies to allocate economic responsibility and decision rights, set performance targets and reward target achievement. PMS should be defined according to an organization's goals, strategy development, benchmarking, human resource management and feedback process of learning organizations and should reflect these considerations accordingly. Organization's objective, strategy development, benchmarking, human resource management and feedback process of learning organization be- come increasingly critical considerations as PMS acts as a self-system of planning and control, signaling, educating and learning as well as goal communication (Henri, 2006a). PMS s are integral part of management control systems (MCSs) which are defined as process of which manager assures that resources are obtained and used effectively and efficiently in the accomplishment of organizations' objectives (Abernethy, Horne, Lillis, Malina \& Selto, 2005). Within this view, PMSs are tools for facilitating organization's objectives and strategies, concerns with strategy implementation or using in a diagnostic way. Alternatively, PMSs are also formal information based routines and procedures managers use to maintain and alter pattern in organization activities or used interactively (Simons, 2000). Besides these two common ways of using PMS, Henri (2006b)

\footnotetext{
* Corresponding author: Alfiandrih

†Email: alfiandri@sgu.ac.id
} 
proposed dynamic approach, a combination of both diagnostic and interactive use of PMS. Research on PMS must focus on manufacturing industry and little research addresses service industry. Hospital is a service industry that provides medical services to patients. Although each hospital provides same type of services, the quality of service performance is different from each other.

The heterogeneous services provided by hospitals contribute to the difficulty in quantifying performance outcomes. Measurement of hospital performance is becoming vague as it is underlain by complexities and sophistication of resources and processes. These conditions create a management control environment whereby monitoring and measuring performance of core operating activities is particularly problematic. At the same time, hospitals relate to the health of human beings. Therefore, government and public who have invested huge amount of money on hospital resources expected that patients should receive appropriate level of health care services i.e. delivering healthcare as efficiently as possible. Given the above scenario, the management of hospital resources is the most important aspect to be monitored and controlled in order to deliver quality medical care services. Failure in optimizing hospital's strategic resources may be due to ill implementation of PMS. PMSs are evidently implemented by hospitals in Indonesia but none of these studies examines specifically their role in monitoring and controlling the resources that enhance hospitals' performance (Anastasia \& Heribertus, 2003; Gunawan, Hasanbasri \& Tjahjono, 2007).

Based on the above scenario, the management of hospital resources is the most important aspect to be monitored and controlled in order to deliver quality medical care services. Failure in optimizing hospitals' strategic resources may be due to ill implementation of PMS. PMSs are evidently implemented by hospitals in Indonesia but none of these studies examines specifically their role in monitoring and controlling the resources that enhance hospitals' performance (Anastasia \& Heribertus, 2003; Gunawan et al., 2007). Furthermore, there is a lack of empirical evidences on the use of PMS in managing hospital's strategic resources. The limited knowledge on the appropriate use of PMS in managing hospital's strategic resources may contribute to the under-achievement of performance in providing standard healthcare services by the Indonesian hospitals. Many hospitals in Indonesia did not meet the standards of medical services by Indonesian government as well as international standards by World Health Organization (WHO). Furthermore, there are lots of complaints by patients about the quality of medical services provided by the hospitals in Indonesia. Following this, two research questions arise: (1) Does the use of PMS, either diagnostically or interactively, influence the strategic resources of hospitals in Indonesia? (2) Are the hospitals' performances enhanced when PMSs are used appropriately in managing these strategic resources? And the objective of this study therefore is to identify the appropriate use of PMS in managing hospital's strategic resources and to determine whether the use of PMS mediates the relationship between strategic resources and hospital's performance.

\section{LITERATURE REVIEW}

\section{Use of Performance Measurement System}

Performance measurement is a basic management technique and has been used since 1910 (Neely et al., 1999; Kurniawati \& MeilianaIntani, 2016). Currently, the use of Performance Measurement System (PMS) does not only consist of monitoring and control but also includes performance measurement, decision making, strategy management, communication, behavioral influence and learning improvement (Simon, 2000). Furthermore, the Performance Measurement Systems (PMS) are comprehensive accountability systems designed to measure and evaluate both financial and non-financial implications of activity performance and results (Abernethy \& Lillis, 2001). The systems ensure the attainment of key success factors and provide scorecards, justify the use of resources as well as provide feedback for driving future improvements.

As an integral part of an organization's Management Control System (MCS), PMS is a management control tool whereby management ensures resources are obtained and used efficiently and effectively to achieve organizational objectives (Abernethy et al., 2005). PMS can play a key role in strategy implementation by helping to translate organizational strategy into desired behaviors and results, communicate expectations, monitor progress, provide feedback, and motivate employees through performance-based rewards. Control of the strategy can be achieved by integrating the four levers of control introduced by Simons (1994). The levers of control consist of (1) belief systems, (2) boundary systems, (3) diagnostic systems and (4) interactive systems. These four control levers are linked with each other as they are working simultaneously although for different purposes. Belief systems are used to enhance core values related to business strategy and to inspire search for new opportunities in line with these values. They are an explicit set of organization definitions that communi- 
cate formally the organization's basic value, purpose and direction. Boundary system reduces risks by setting limits to strategically undesirable behaviors. They are an explicit set of organizational definitions and parameters, expressed in negative or minimum term. Diagnostic control system is used to motivate, monitor and reward achievement of specified goals. Interactive control system is used to stimulate search and learning, allowing new strategies to emerge as participants throughout organization to respond to perceived opportunities and threats.

Although it had been proposed that all the four levers of control should be working simultaneously to achieve comprehensive control, in the context of controlling strategy through PMS the feedback and measurement systems (i.e. diagnostic and interactive systems) are more transparent and objective to be used in influencing the employee behaviors towards organizational goals. The purpose of belief and boundary systems is to inspire organization search and discovery without prescribing the precise nature of activities. They explicitly delineate the acceptable domain of activity for organizational participants in terms of positive ideals and prospective limit. Within this acceptable domain of activity, diagnostic system helps to implement intended strategy and diagnostics system helps to adapt to competitive advantages. Furthermore, belief and boundary systems focus on ethical issue therefore they are difficult to measure (Tuomela, 2005).

Diagnostic use of PMS is embedded in a cybernetic model of control while diagnostic control systems allow managers to manage the results or output of the objective, an interactive system control is forward-looking and characterized by active and frequent dialogue among top managers. As Henri (2006b) argued, Interactive use of MCS represents the positive force as MCS in its ability to expand opportunity seeking and learning throughout the organization. Generally, Interactive system control is forwardlooking and characterized by active and frequent dialogue among top managers. Interactive use of PMS provides feedback through the communication among managers to find and observe the new strategies in achieving the objective of the firm. By doing this, the interactive use of PMS provides double loop learning.

Henri (2006b) proposed that the joint use of PMS in diagnostic and interactive manner which creates dynamic tension reflecting competition (both positive and negative feedback) and also complementary view of strategy (both intended and emergent strategies). In this way, strategic resources can be managed by using dynamic use of PMS that leads to organizational performance. However, his proposed approach i.e. dynamic approach is a theoretical one that includes stated objectives or goals, a predictive model and tool to facilitate the choice of alternative actions (Mundy, 2010). Within this view, PMS provides an avenue for comparing actual results and strategic goals that enable managers to track the progress on strategy implementation and to make the appropriate corrections. Generally speaking, diagnostic system is used to implement intended strategy and also provide motivation and direction to achieve goals by focusing on and correcting deviations from pre standards of performance (Henry, 2006; Widener, 2006b). Since it signals the success of the most critical factors of the intended strategy, diagnostic system of PMS only provides one-way feedback with a single loop learning (Tuomela, 2005) concept without clearly defining how the combination should be. The measurement of dynamic approach is based on the interaction terms between diagnostic and interactive use of PMS variables. Therefore, this study concentrates only on the two extreme ways of PMS usages; diagnostic and interactive.

\section{Hospital Strategic Resources}

Strategic resources are the resources of the firm that are not imitable, must be rare and must be valuable so that the firm can sustain a competitive advantage (Barney, 1991; Widener, 2006a). Generally, strategic resources must be different between a one firm and another in order to achieve sustained performance in the competitive business arena. Besides these characteristics of strategic resources, firm resources need to be organized in such a manner that it can exploit its full potential. Resources are viewed as bundles of assets (tangible and intangible assets) and capabilities (knowledge and skills) that firms own. Specifically, Amit \& Schoemaker (1993) identified three types of potential strategic resources namely (1) physical resources (2) structural resources and (3) human resources including employee knowledge and skills. This classification of strategic resources is also applied in hospital settings.

Widener (2007) argued that human capital is highly heterogeneous resource within industry and between groups of industries, and it is not exceptional in hospital setting. Hospital much relies on human capital because it requires adaptive individuals who have excellent problem solving skills, and the ability to make allocative decision. Individual knowledge, skills and the ability to interact with employees and patients are the primary resources embedded in the hospital setting. In addition to this, human capital is an im- 
portant source and viewed as the key success factor since it is usually the primary strategic interface between hospital and patients. Human resources in hospital include doctors, nurses and management team who provide hospital with a competitive edge.

Structural resource is the supportive infrastructure for human resources, as it is defined as the knowledge that has been captured and converted into systems through organizational routines, practice, process, new technology and patents/license and therefore owned by firms (Widener, 2006a). Structural resource in hospital includes operation practices such as, lean delivery practices and it could be new medical tracking information system and development of new programs with medical technology or procedures.Physical capital resource includes tangible, "hard" assets owned by the firms, for example, geographic location and other fixed assets. In addition, physical resources are recorded on the firm's balance sheet and are more easily tracked and monitored through traditional financial measures (Widener, 2006a). Physical resources in hospital include state-of-the-art medical facilities and equipment that allow them to provide faster, more efficient and higher quality of service.

\section{METHODOLOGY}

The hypotheses developed in this study are underpinned by resource based theory. Under this theory, organization's resources that consist of human resources, structural resources and physical resources are considered as unique resources of value creation which hold organizations together and help them to sustain competitiveness. As key inputs to strategy and sources of competitive advantages, these resources should be properly managed using tool such as PMS in order to realize their optimal benefits of high performance to customers i.e. hospital patients. By using PMS appropriately, organization could fully gain benefits of both instrument aspect of performance measures and behavioral aspect of influencing employee behaviors toward organization goals. Thus, further enhancement of the hospital's performance is required.

\section{Human Resources Use of PMS and Hospital's Perfor- mance}

Human resources are an important source and play a supportive role in ensuring strategic success particularly in hospitals. Hospitals rely heavily on human capital with a focus on specialized knowledge and clear communication and interaction between employees and patients (Widener, 2006a, Mahdieh, 2015). For example, hospitals rely on the competency of the doctor and his/her professionalism to determine patient's satisfaction. The doctor's treatment plays a significant role in meeting the expectations of patient's satisfaction. Other examples are, do doctors take their patients seriously, or, do doctors pay sufficient attention to their patients, and, do doctors make the right diagnosis (Van Der Schee, Groenewegen \& Friele, 2006). By diagnostically using PMS human resources can be controlled, monitored and also motivated by looking at their behaviors. Employees' behaviors are normally controlled and monitored based on job tasks, attendance and ethics. By interactively using PMS with top management involvement, it creates dialogue between managers and employees and sharing information, thus stimulating learning. Interactive use of PMS starts by communicating to employees to give better understanding about their strengths and weaknesses. By knowing current practices and trends of employees, management can project future performance. For example, by gaining information of poor customer service for elderly patients, management then can implement training and workshop to improve patient-doctor relationship, which may lead to increase customer satisfaction and consequently improve hospital's performance. Therefore, the following are hypothesized:

H1a: The diagnostic use of PMS mediates the relationship between human resources and hospital's performance.

H1b: The interactive use of PMS mediates the relationship between human resources and hospital's performance.

\section{Structural Resources Use of PMS and Hospital's Per- formance}

Structural resources of the hospital much rely on the information system, new technology and innovation. These resources are used in day-to-day operations and administration in providing healthcare services to the patients. By using PMS diagnostically, structural resources can be monitored through the operations of the business. For example the use of CT-Scan, how many hours operated and by whom, is monitored by internal network. Meanwhile, interactive use of PMS is looking at the function of the technology, from the output or results of the operations. Hence, this leads to high hospital's performance. Therefore, the following are hypothesized:

H2a: The diagnostic use of PMS mediates the relationship between structural resources and hospital's performance.

H2b: The interactive use of PMS mediates the relationship between structural resources and hospital's performance. 


\section{Physical Resources Use of PMS and Hospital's Perfor- mance}

Physical resources are tangible assets which include land, building, equipment and other fix assets which are owned by the firm. To measure physical resources in PMS, it can be applied only in diagnostic way. This is because physical resources cannot be easily changed. For example, building and equipment are tangible assets that cannot be changed, renovated or extended in the short period because they incur high cost which requires serious consideration by managers to implement it. Physical resources can be controlled and monitored through financial performance. By looking at depreciation, spending costs and other financial measures therefore, physical resources are easy to track, monitor and control. The following hypothesis is proposed: H3: The diagnostic use of PMS mediates the relationship between physical resources and hospital's performance.

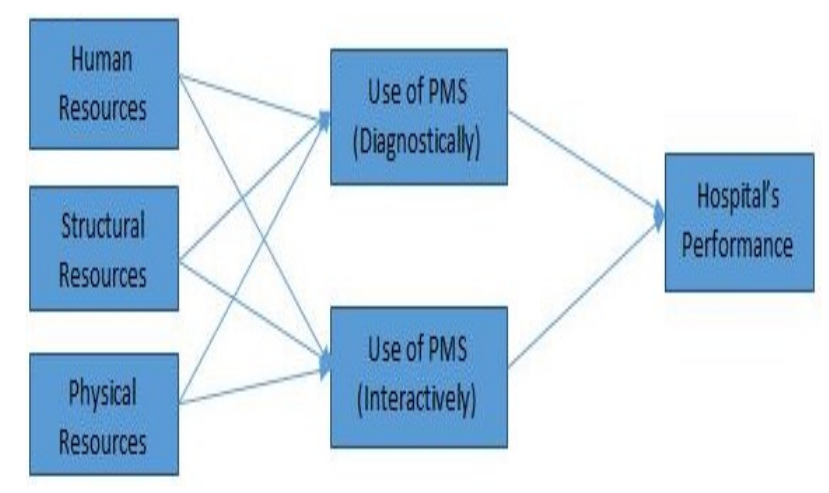

FIGURE 1. Research Framework

\section{Method}

Data were collected from public hospitals and private hospitals in Indonesia using survey questionnaires. A list of hospitals provided by the Indonesian Health Care Department was used as sampling frame and sample was selected using purposive sampling. The study chose region as criteria for selecting sample. West Indonesia was chosen as sample because of its highest population compared to other parts of Indonesia. The West Indonesia region includes Sumatra Islands and the capital city of Jakarta. With the highest population, the range of hospital sizes was reflected as the hospital locations spread from cities, sub urban to rural areas. Furthermore, administration of hospitals is similar as hospitals are subjected to the regulation of Indonesian health care systems since Dutch colonial system was no longer implemented since 1949. In total there are 500 hospitals in West of Indonesia. The sample was then further se- lected based on locations; capital cities of province, district of province and capital city of Jakarta. Questionnaires were sent to 200 hospitals using mail and self-administrative approaches. A total of 160 hospitals returned the questionnaires and all were usable to use for data analysis, which represents $80 \%$ of rate of return.

TABLE 1. Profile of the respondent

\begin{tabular}{|c|c|c|}
\hline Measuring Factors & Frequency & Percent \\
\hline \multicolumn{3}{|l|}{ Name of Hospital } \\
\hline University Hospital & 4 & 2.5 \\
\hline Public Hospital & 6641.3 & \\
\hline Private Hospital & 87 & 54.4 \\
\hline Specialist Hospital & 3 & 1.9 \\
\hline \multicolumn{3}{|l|}{ Bed Capacity } \\
\hline Less than 50 & 18 & 11.3 \\
\hline $50-100$ & 58 & 36.3 \\
\hline $101-200$ & 49 & 30.6 \\
\hline More than 200 & 35 & 21.9 \\
\hline \multicolumn{3}{|l|}{ Position } \\
\hline Director of Hospital & 20 & 12.5 \\
\hline Chief Director & 17 & 10.6 \\
\hline Head Department & 42 & 26.3 \\
\hline Others & 81 & 50.6 \\
\hline \multicolumn{3}{|l|}{ Working Tenure } \\
\hline Less than 2 years & 42 & 26.3 \\
\hline $2-5$ years & 60 & 37.5 \\
\hline $6-10$ years & 31 & 19.4 \\
\hline More than 10 years & 27 & 16.9 \\
\hline \multicolumn{3}{|l|}{ Education } \\
\hline General doctor & 38 & 23.8 \\
\hline Specialist doctor & 22 & 13.8 \\
\hline Undergraduate nursing & 29 & 18.1 \\
\hline Other graduates & 71 & 44.4 \\
\hline
\end{tabular}

The unit analysis of the research is hospital organization. The questionnaire was distributed to Chief Medical Director, Deputy Director, Manager of Finance and Head of Research and Development. They are suitable respondents as they are involved directly in management of resources and implementation of the hospital's administrative systems including performance measurement system (PMS). Table 1 shows the respondents' profile. Initially, the questionnaire was developed from existing instruments. To enhance the face validity, the questionnaire was pre tested on two hospital directors, head of nurses and head of financial department. Suggestions from the pre-test were then incorporated in the questionnaire, and pilot test was done on two public hospitals and two private hospitals in Banda Aceh. Since there is no change in the questions, the results of the pilot test were used for final analysis.

\section{Measurement of the Variables}

Strategic resources were measured by using instruments of (Sitawati, Manaf \& Winarti; 2009, Abernethy et al., 2005, 
Van Der Schee et al., 2006; \& Widener; 2007, 2006a). Human resources refer to knowledge and skills possessed by the employees, using a scale of 1 to 5 , where 1 is "highly unfavorable" and 5 is "highly favorable". Structural resources refer to information system, computer programming and technology, using scale of 1 which was considered "highly unfavorable" to 5 which was considered "highly favorable". Physical resources refer to tangible assets of the hospital, using a scale of 1 to 5 , where 1 represented physical resources to be "totally unimportant" to 5 to be "totally important".

Instruments from Widener (2006b) and Henri (2006a) were adopted to measure the use of PMS. Diagnostic use of PMS is tool used by management to assist them in controlling, monitoring, signaling and learning purposes using a scale 1 to 5 where a 1 is "small extent" and 5 is "large extent". The score of one represented the small role of diagnostics in the hospital and the score of five represented that diagnostics play an important role in the hospital's performance. Interactive uses of PMS, on the other hand are forward-looking and characterized by active and frequent dialogue among top managers and measured by using scale 1 to 5 , where 1 represented total disagreement and 5 total agreement. There were three questions reverse coded. Hospital's performance is defined as hospital's ability to compete with other hospitals in the market. It was measured using instruments by Cheng Lim, Tang \& Jackson (1999) and Widener (2006b). The measure of hospital's performance incorporates both financial and non-financial performance. A five-point Likert scale was used where 1 was "significantly lower" and 5 was "significantly higher" compared with other hospitals.

\section{Factor Analyses}

The measures are also subject to factor analysis. Items with factor loading more than 0.5 and cross loading not more than 0.3 were retained. The Cronbach's alpha for all variables was higher than 0.80 indicating the measures are reliable (Nunnally, 1978; Widener, 2007). Table 2 until Table 4 shows the result of factor analysis and reliability test on strategic resources, use of performance measurement systems and hospital's performance.

TABLE 2 . Strategic resources - factor analysis and reliability test

\begin{tabular}{|c|c|c|c|}
\hline Variable items & Human Resource & Structural Resource & Physical Resource \\
\hline $\begin{array}{l}\text { Staff and medical staff capabilities in healthcare deliv- } \\
\text { ery }\end{array}$ & .837 & & \\
\hline Staff and medical staff in coping with crisis & .808 & & \\
\hline Top managers' personal relationship with staff & .793 & & \\
\hline Individual ability to work in the team & .776 & .333 & \\
\hline Interaction with patient & .746 & .369 & \\
\hline Technology as "state of art" facilities & & .824 & \\
\hline $\begin{array}{l}\text { Technology has to be specialized, customized or } \\
\text { unique }\end{array}$ & .352 & .821 & \\
\hline Completeness of information system & & .757 & \\
\hline $\begin{array}{l}\text { Information system for clinical and medical service } \\
\text { operation }\end{array}$ & & .755 & \\
\hline IS for internal communication e.g. LAN & & .747 & .823 \\
\hline Building and Vehicle & .315 & & .775 \\
\hline Non-medical equipment e.g. computer & .400 & & .740 \\
\hline Laboratory equipment and information system & & .735 & \\
\hline Financial assets e.g. cash on hand, financial capital & & & \\
\hline Cronbach's alpha & .904 & .901 & .836 \\
\hline
\end{tabular}

TABLE 3. Use of PMS - factor analysis and reliability test

\begin{tabular}{lcc}
\hline \hline Variable items & Diagnostically & Interactively \\
\hline Monitor the results & .849 & .790 \\
Track progress toward goals & .769 \\
Compare the outcomes with expectation & .758 \\
Review key measures & .650 & .851 \\
Enable discussion in meeting of superiors, subordinates and peers & .629 & .837 \\
Provide a common view of organization & & .783 \\
Top Management pays day to day attention to PMS & & .813 \\
Operating managers are frequently involved with the PMS & .862 & \\
Top management interprets information from PMS & & \\
Cronbach's alpha & & \\
\hline \hline
\end{tabular}


TABLE 4 . Hospital's performance - factor analysis and reliability test

\begin{tabular}{lcc}
\hline \hline Variable items & Non-financial & Financial \\
\hline $\begin{array}{l}\text { Responding to patients' } \\
\text { requests }\end{array}$ & .901 & .340 \\
$\begin{array}{l}\text { Responding to patients' } \\
\text { complaints }\end{array}$ & .888 & .341 \\
$\begin{array}{l}\text { Quality of clinic } \\
\text { Maintaining high capac- }\end{array}$ & .741 & \\
ity utilization & .708 & \\
Return On Investment & & \\
(ROI) & & .882 \\
Operating profit & & .866 \\
Return On Assets & .347 & .826 \\
Cronbach's alpha & .880 & .888 \\
\hline \hline
\end{tabular}

\section{RESULTS}

\section{Data Analysis}

This study used Structural Equation Modelling (SEM) to test the hypotheses simultaneously on the whole research framework to determine the extent to which it is consistent with the data. SEM is statistical methodology that takes a confirmatory i.e. hypothesis-testing approach to analyze structural theory bearing on some phenomenon (Byrne, 2013). It can also capture the mediating effect of PMS usage on the relationship between strategic resources and hospital's performance. Due to the small sample size of 160 hospitals, the study variables were treated as manifest variables using summated scores.

The treatment as manifest variable in SEM is used in order to reduce the number of parameters that must be estimated and often used due to small sample size (Widener, 2006a \& 2006b; Baines \& Langfield-Smith, 2003). SEM was conducted using AMOS 18. Before running the model, the manifest variables were inspected for any possible abnormalities using SPSS statistical data analysis. The variables were checked for normality distribution, outliers and multicollinearity. Only univariate outlier existed with five cases having score more than \pm 3.0 and deleted from final analysis. The data therefore do not violate normality and multicollinearity assumption. This study used the Chi-square and it was divided as follows: by the model degree of freedom (df), the comparative of fit index (CFI), the goodness of fit index (GFI) and the root mean square error of approximation (RMSEA), as indicator of model fit. To assess fit of a SEM, the general standard must be achieved. The $\mathrm{X}^{2}$ is $29.682(p<0.01)$. The comparative of fit index (CFI) is 0.95 , the goodness of fit (GFI) index is 0.943, RMSE < 1.00 (Byrne, 2013). In addition, the level of coefficient is 0.5. Initially, all variables are run simultaneously as in Figure 1. However, this base model does not fit with the requirements of good fit. Therefore, alternative model treating strategic resources as independent was used. This is supported by an alternative model is better than a base model if it meets the indicator model fit. Even though strategic resources are treated equally under resource-based theory, this is an exception in Indonesian hospitals due to different functions of each resource. Human resources are regarded as the most important in hospitals due to heavy reliance on knowledge, skills and experience of their staff (medical as well as non-medical staff) in delivering medical services to patients. Physical and structural resources are considered as complementary resources to human resources in hospital. Without these resources, the human resources could not perform well when delivering medical services. For instance, without healthcare equipment, doctors could not detect diseases accurately.

Although they could diagnose the diseases based on their knowledge and experiences, it is not sufficiently enough to come out with an accurate diagnosis. Another example is building which provides places such as clinics and wards for patients to be treated by the doctors and nurses. Similarly, without proper technology and information system the doctors could not access full information on patients' medical reports quickly. Therefore, this will affect the process of curing the patients. In this function, technology and information system i.e. structural resources play significant role in transferring information regarding patients in the process of delivering medical services. Coupled with this, internal network is also important as to control the staff's behaviors such as controlling staff attendances, day-to-day operation etc.

The final results presented in Table 5 until Table 7 had gone through process of deleting and adding paths to improve the model fit. Basically two paths are added (1) nonfinancial performance to financial performance to capture the significant relationship of importance of non-financial performance on financial performance and (2) interactive to diagnostic to reflect the dynamic approach proposed by Henri (2006b).

\section{Human Resources, Use of PMS and Hospital's Perfor- mance}

Table 5 shows the model fit with the general standard of SEM which is the Chi-square 8.767, df 5 and $p$-value is .119 
$(p<0.01)$, cfi is .987 ( $>0.95)$, Rmsea is .070 ( $>1.00)$ and GFI .978. This indicates a good fit of the model. The relationship among variables is also quite significantly correlated as it shows in figure 2, model A. The level of correlation 0.5, HR to Diag is 0.549 , from Diag to NFP .680, $(p<.01)$. The indirect effect of HR on NFP is $0.37\left(.549^{*} .680\right)$ through using PMS diagnostically.

Indirect effects are calculated as the products of decomposed path coefficient (Kline 1998). In addition, path coefficient from NFP and FP is .535, $p<.01$ strengthens the argument that hospital focuses on quality delivery services which subsequently increased financial performance. Thus H1 is supported.On the other hand, interactive use of PMS must be combined with diagnostic approach to enhance non-financial performance.

The path coefficient from HR to INTR is .537, $p<.01$ and from INTR to DIAG is .198, p<.01. The INTR mediates the relation of HR with a significant indirect effect of .11 $\left(.537^{*} .198\right)$ on DIAG of PMS. Using PMS both of INTR and DIAG leads to NFP $(.680, p<0.1)$. The total effect is 0.79 $(.11+.680)$. This subsequently leads to FP with path coefficient of $.540(p<.01)$. Thus, H1b is rejected.

TABLE 5 . The Relationship of human resources, use of PMS and hospital's performance

\begin{tabular}{lcc}
\hline \hline Variables & $\begin{array}{l}\text { N155 Chi square (df) 8.767(5) p-value.119 cfi .987 Rmsea .070 GFI.978 } \\
\text { Coefficient }\end{array}$ & p-value \\
\hline HR- Diag & .549 & $* * *$ \\
HR- INTR & .537 & $* * *$ \\
INTR- Diag & 198 & .005 \\
Diag- NFP & .680 & $* * *$ \\
NFP-FP & .535 & $* * *$ \\
\hline \hline
\end{tabular}

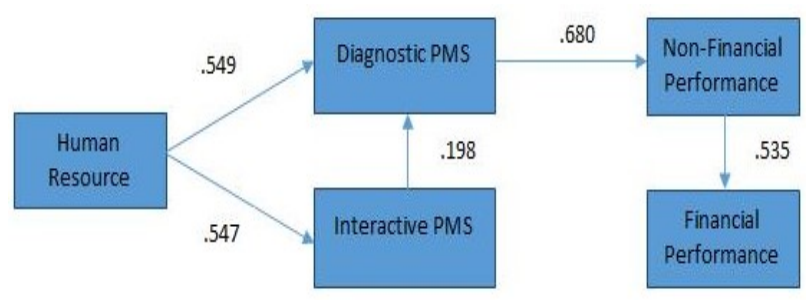

FIGURE 2. Model A: HR, Use of PMS and hospital's performance

\section{Structural Resources, Use of PMS and Hospital's Perfor- mance}

Table 6 shows the model fit with the general standard of SEM where the Chi-square is 3.030 , $\mathrm{df} 3$ and $p$-value is .387 $(p<0.01)$, cfi is $1.000(>0.95)$, Rmsea is $.008(>1.00)$ and GFI
.992. This indicates a good fit of the model. As it shows in figure 2, model $\mathrm{B}$, the relationship among variable in structural resources is uniquely correlated which is SR to Diag is $0.575, p<.01$ and from Diag to NFP is .410, $p<.01$, supporting the mediating role of PMS in managing structural resources in enhancing hospital's non-financial performance. SR has an indirect effect of .235 (.575*.410) on NFP through using PMS diagnostically. The link between NFP and FP existed with significant path coefficient between both variables $(.360, p<.01)$.

Thus, H2a is supported. Same as in human resources, PMS usage should be used in combination interactively first and then diagnostically in managing structural resources. Path coefficient from SR to INTR is .454, $p<.01$ and from INTR to Diag is $.232, p<.01$. The indirect effect of INTR in mediating relation of SR is $.105\left(.454^{*} .232\right)$ on diagnostic PMS. This combination leads to NFP $(.410, p<0.1)$, with total effects of overall path equal to 0.515 . Subsequently, it leads to FP with coefficient of $.360, p<0.1$ respectively. Thus $\mathrm{H} 2 \mathrm{~b}$ is rejected. Based on the findings, the diagnostic use of PMS mediates the relationship between structural resources to non-financial performance and leads to financial performance.

Interactive use of PMS supports to enhance the role of diagnostic use of PMS that can improve non-financial performance and subsequently leads to financial performance. Besides this, there are direct relationships between structural resources and financial and non-financial performance.

TABLE 6 . The relationship of structural resources, use of PMS and hospital's performance

\begin{tabular}{llc}
\hline \hline Variables & \multicolumn{2}{c}{ N 155 Chi aquare (df) $3.030(3)$ p-value .387 cfi .1000 Rmsea .008 GFI .992 } \\
& Coefficient & p-value \\
\hline SR - Diag & .575 & $* * *$ \\
SR - INTR & .454 & $* * *$ \\
INTR - Diag & .232 & $* * *$ \\
Diag - NFP & .410 & $* * *$ \\
NFP - FP & .360 & $* * *$ \\
SR - NFP & .279 & $* * *$ \\
SR - FP & .243 & 0.04 \\
\hline \hline
\end{tabular}

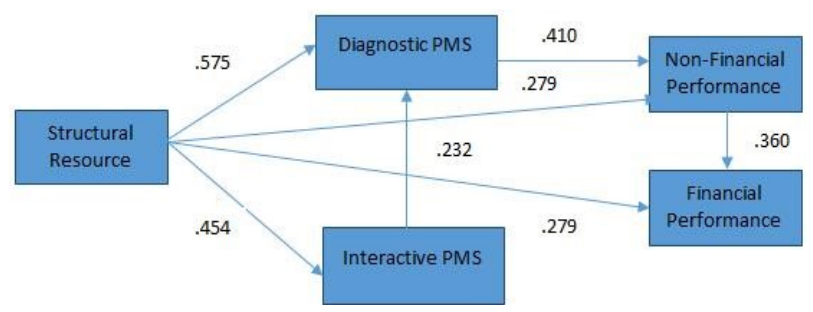

FIGURE 3. Model A: HR, Use of PMS and hospital's performance 


\section{Physical Resources, Use of PMS and Hospital's Perfor- mance}

Table 7 shows the model physical resources fit with the general standard of SEM which has the Chi-square of 4.351, df 3, $p>246$ ( $p<0.01)$, CFI of .996 (>0.95), Rmsea of .054 (>1.00) and GFI .989. This indicates fit model. Similar with structural resources, figure 3 model C shows the relationship among variables that are correlated. It shows the correlation between PR to Diag is 0.407, Diag to NFP is 0.586 . The indirect effect of PR to NFP through Diag is .23 (.407*.586). In addition, path coefficient from NFP to FP is .445, $p<.01$ indicates the link between FP and NFP. Thus, H3a is supported. Similar with the results in Table 5 and Table 6 , the model shows that path coefficient PR to INTR is .401, $p<.01$ and from INTR to Diag is .403, $p<.01$. The indirect effect of these paths is .16 (.401*.403). From Diag to NFP, the coefficient is .586, $p<.01$. Therefore, the total effect of these paths is $.746(.16+.586)$. The model also shows that there is a direct effect between PR to NFP $(.261, p<.01)$ and FP $(.255$, $p<.01)$. The NFP mediates relationship between PR and FP. The indirect effect of PR is .06 (.261*.255). The stronger link between NFP and FP indicates that the improvement of physical resources is to enhance quality medical services rather than increase profitability of hospital.

TABLE 7. The relationship of Physical resources, use of PMS and hospital's performance

\begin{tabular}{llc}
\hline \hline Variables & $\begin{array}{l}\text { N 155 Chi aquare (df) 4.351 (3) p-value .226 cfi .996 Rmsea .054 GFI.989 } \\
\text { Coefficient }\end{array}$ & p-value \\
\hline PR-Diag & .407 & $* * *$ \\
PR-INTR & .401 & $* * *$ \\
INTR-Diag & .403 & $* * *$ \\
Diag-NFP & .586 & $* * *$ \\
NFP-FP & .445 & $* * *$ \\
PR-NFP & .261 & $* * *$ \\
PR-FP & .255 & .001 \\
\hline \hline
\end{tabular}

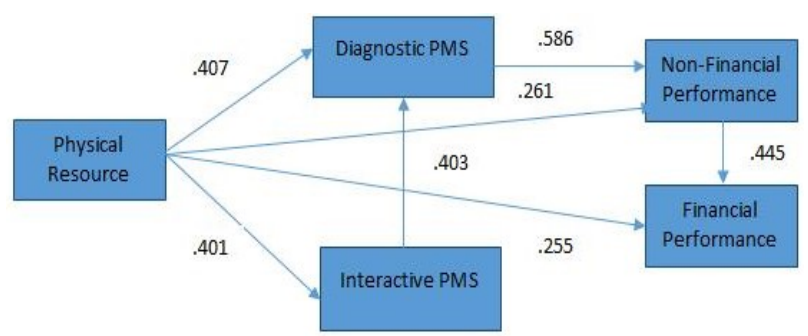

FIGURE 4. Model C: PR, Use of PMS and hospital's performance

TABLE 8. Summary of hypotheses testing

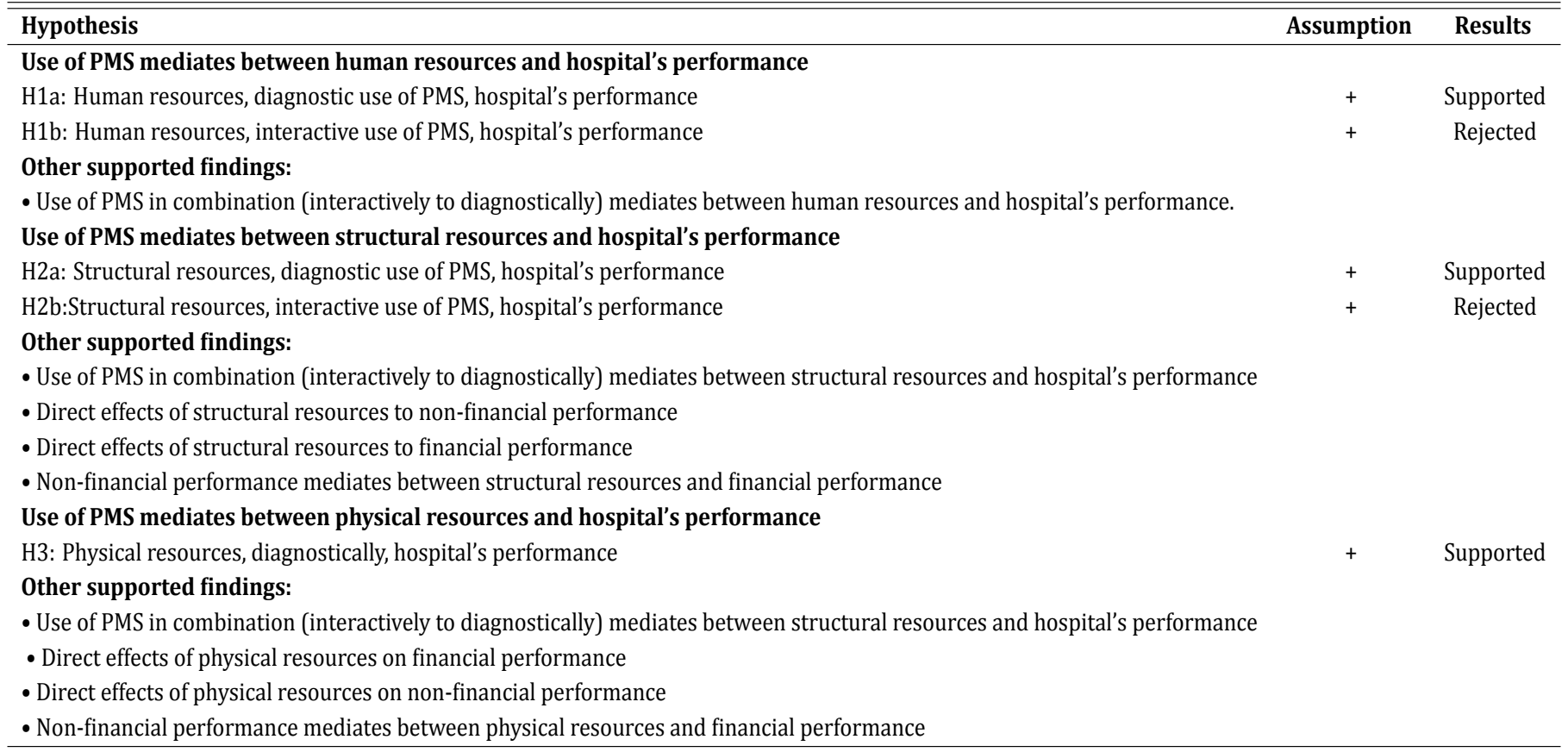

\section{DISCUSSION AND CONCLUSION}

Based on the data analysis of this study, strategic resources of hospitals in Indonesia must be treated independently although it is argued that these resources must be treated equally under resource based theory. This is because the function of each hospital's strategic resources is different from each other, and viewed as complement with each other. Physical resources, for example, are considered as a complementary resource in supporting medical services to the patients. Even though, it is not as important as hu- 
man resources and structural resources, physical resources contribute to accuracy of diagnosing patients' illness. An example of this would be the use of healthcare equipment, in which without them, doctors and nurses could not be able to detect diseases for the patients. Although doctors or nurses could infer a diagnosis based on their knowledge and experiences, it would not be as precise as it would be with the assistance of healthcare equipment.

Human resources are managed diagnostically to enhance the healthcare service performance. Interactive ways of PMS, on the other hand, provide inputs for hospital management as well as channels of communication for controlling and monitoring employees. Although PMS seems to be used interactively, the use is more towards learning purposes in order to monitor employee behaviors thus giving top management more authority. This indicates that human resources must be necessarily controlled and supervised strongly by the hospital management in order to improve healthcare services to the patients. Although dynamic approach exhibited in this study is not the same as Henri's (2006a) concept, it provides evidence on the interrelations between different uses of PMS. The use of interactive PMS enhances the role of diagnostic PMS to improve non-financial performance that leads to high financial performance. Additional information on strategies from interactions among managers provides top management with better knowledge of control and monitor for firm strategies.

Structural resources, i.e. information system and new technology, are managed diagnostically to enhance the quality service of healthcare. Structural resources can be monitored during the operation of the business. For example, CT-scan and ICU machines can be controlled by looking at how many hours a machine is operated and by whom. Interactive use of PMS supports diagnostic use of PMS as an addition to enhance the role of diagnostically managing structural resources. The role of the interactive use of PMS is to avoid unnecessary information collection; therefore, the management of various hospitals could give more attention to the control and monitoring of structural resources. Similarly, with human resources, structural resources are also managed by using PMS dynamically, but again, it is not similar with what was conceptualized by Henri (2006b) where the interactive use of PMS is directly related to hospital's performance. Practically, the combination of diagnostic and interactive use of PMS is to enhance the role of diagnostically improving non-financial performance that leads to financial performance. In other words, the dynamic use of PMS is to enhance the role of controlling and monitoring structural resources, and to enhance medical service quality that leads to financial performance. On the other hand, without mediating the use of PMS, structural resources bear a direct relationship to non-financial performance and financial performance. This indicates that the use of PMS as a mediating variable is not necessarily significant to enhance a hospital's performance, even though information systems and technology still need to be controlled and monitored by hospital management. It is argued by hospital management, "Technology and information system must be controlled. It is about programming in the technology. These programs must provide enough information regarding illness of the patients. The information must be efficient. It is to avoid waste of the information. Waste of the information will impact our costs"(Financial Manager, RSTF).

Physical resources are controlled and monitored by looking at financial performance. The hospital management always makes financial statements, i.e. monthly, quarterly, semester and yearly, to perceive costs and expenses which have already been spent in order to look after the tangible assets of a hospital. Therefore, by looking at depreciation, spending costs and other financial figures, physical resources can track, monitor and control appropriately, that is diagnostic use of PMS in managing physical resources. Meanwhile, the role of interactive use of PMS is to provide incremental information for diagnostic use of PMS which can lead to the improvement of the quality of healthcare services and can affect the financial performance. Similarly, with two other resources, i.e. human resources and structural resources, dynamic use of PMS can also be implemented in managing physical resources. Therefore, by combining both approaches, i.e. diagnostic and interactive use of PMS, control and monitoring of tangible assets by hospital management can be enhanced. Again, this opposes the dynamic use of PMS as conceptualized by Henri (2006a) where both diagnostic and interactive use of PMS have a direct effect on hospital's performance. On the other hand, similar with structural resources, without mediating the use of PMS, physical resources have a direct relationship to non-financial performance and financial performance. It indicates that the role of using PMS as a mediating variable is not necessarily significant enough to enhance hospital's performance even though all tangible assets still need to be controlled and monitored by hospital management.

Understanding the managing of strategic resources, i.e. human resources, structural resources and physical resources, through the dynamic use of PMS need to be adjusted from what has already been conceptualized. Henri 
(2006b) proposed that both of diagnostic and interactive use of PMS have similar roles that enhance organizational performance, however the role of dynamic use of PMS in the hospital in the Indonesian context is not the same as what Henri (2006b) proposed. This has been shown through the results and analysis of this study. The role of interactive use of PMS is not to support increased hospital's performance but instead to support the role of diagnostics as a control and monitoring of strategic resources in order to improve health service quality and to lead to financial performance. This study has several limitations. Firstly, results of the study cannot be generalized to all population in Indonesia especially for Middle Indonesia and East Indonesia. Lack of sample in Middle of Indonesia and East of Indonesia, this study therefore, cannot be justified. Secondly, sample of the hospitals was not divided into two: public and private. The results might have been different due to the objective between public and private hospital. Thirdly, due to use of PMS as mediator, therefore, this study does not examine with or without use of PMS more dominant to enhance hospital's performance.

\section{REFERENCES}

Abernethy, M.A., \& Lillis, A.M. 2001. Interdependencies in organization design: a test in hospitals. Journal of Management Accounting Research, 13(1): 107-129. D0I: 10.2308/jmar.2001.13.1.107

Abernethy, M.A., Horne, M., Lillis, A.M., Malina, M.A., \& Selto, F.H. 2005. A multi-method approach to building causal performaps from expert knowledge. Management Accounting Research, 16(2): 135-155.

DOI: $10.1016 /$ j.mar.2005.03.003

Amit, R., \& Schoemaker, P.J. 1993. Strategic assets and organizational rent. Strategic Management Journal, 14(1): 33-46. DOI: $10.1002 / \mathrm{smj} .4250140105$

Anastasia, V.N., \& Heribertus, A.P. 2003. Interdependensi antara inovasi jasa, struktur otonomi, system pengendalian kinerja dan organizational outcomes. Kinerja, 7: 57-69.

Baines, A., \& Langfield-Smith, K. 2003. Antecedents to management accounting change: A structural equation approach. Accounting, Organizations \& Society, 28(7): 675-698. DOI: 10.1016/S0361-3682(02)00102-2

Barney, J. 1991. Firm resources and sustained competitive advantage. Journal of Management, 17(1): 99-120.

DOI: $10.1177 / 014920639101700108$

Byrne, B.M. 2013. Structural equation modeling with AMOS: Basic concepts, applications, and programming. Abingdon, UK: Routledge.

Cheng Lim, P., Tang, N.K., \& Jackson, P.M. 1999. An innovative framework for health care performance measurement. Man- $\boldsymbol{a g}$ -

ing Service Quality: An International Journal, 9(6): 423-433. DOI: 10.1108/09604529910304125

Gunawan, W.S., Hasanbasri, M., \& Tjahjono K. 2007. Kinerja rumahsakit pemerintah dan swasta: Studi implementasi

manajemen strategis dengan system manajemen akuntabilitas kinerja. Unpublished thesis, Universitas Gadjah Mada, Yogyakarta, ID.

Henri, J.F. 2006a. Management control systems and strategy: A resource-based perspective. Accounting, Organizations \& Society, 31(6): 529-558. DOI: 10.1016/j.aos.2005.07.001

Henri, J.F. 2006b. Organizational culture and performance measurement systems. Accounting, Organizations \& Society, 31(1): 77-103. DOI: 10.1016/j.aos.2004.10.003

Kurniawati, E.P., \& MeilianaIntani, A. 2016. Effect analysis of the use of accounting information, managerial performance and employee performance Towards SMEs. Journal of Administrative \& Business Studies, 2(3): 130-142.

Merchant, K.A., \& Van der Stede, W.A. 2007. Management control systems: Performance measurement, evaluation and incentives. California, CA: Pearson Education.

Mundy, J. 2010. Creating dynamic tensions through a balanced use of management control systems. Accounting, Organiza\& Society, 35(5): 499-523. DOI: 10.1016/j.aos.2009.10.005

Mahdieh, 0. 2015. Interaction between communication and organizational conflict and its relationship with performance. International Journal of Business \& Administrative Studies, 1(2): 54-60.

Neely, A., Mills, J., Platts, K., Richards, H., Gregory, M., Bourne, M., \& Kennerley, M. 2000. Performance measurement system design: Developing and testing a process-based approach. International Journal of Operations \& Production Manage- ment, 20(10): 1119-1145. DOI: 10.1108/01443570010343708 
Nunnally, J.C. 1978. Psychometric theory. New York, NY: McGraw-Hill.

Simons, R. 1994. How new top managers use control systems as levers of strategic renewal. Strategic ManagementJour- $\quad$ nal, 15(3): 169-189. DOI: $10.1002 /$ smj.4250150301

Simons, R. 2000. Performance measurement and control systems for implementing strategy. Upper Saddle River, NJ:

Prentice Hall.

Sitawati, R., Manaf, S., \& Winarti, E. 2009. The application of human resource scorecard: A case study of public hospitals in NTT province, Indonesia'. International Bulletin of Business Administration, 4(1): 23-27.

Tuomela, T.S. 2005. The interplay of different levers of control: A case study of introducing a new performance measure- ment system. Management Accounting Research, 16(3): 293-320. D0I: 10.1016/j.mar.2005.06.003

Van Der Schee, E., Groenewegen, P.P., \& Friele, R.D. 2006. Public trust in health care: A performance indicator? Journal of

Health Organization \& Management, 20(5): 468-476. DOI: 10.1108/14777260610701821

Widener, S.K. 2006a. Associations between strategic resource importance and performance measure use: The impact on

firm performance. Management Accounting Research, 17(4): 433-457. D0I: 10.1016/j.mar.2005.10.002

Widener, S.K. 2006b. Human capital, pay structure, and the use of performance measures in bonus compensation. Manage- ment

Accounting Research, 17(2): 198-221. D0I: 10.1016/j.mar.2005.06.001

Widener, S.K. 2007. An empirical analysis of the levers of control framework. Accounting, Organizations \& Society, 32(7):

757-788. DOI: 10.1016/j.aos.2007.01.001

- This article does not have any appendix. - 